\title{
The role of small-bowel endoscopy in inflammatory bowel disease: an updated review on the state-of-the-art in 2021
}

\author{
Alexandros Skamnelos ${ }^{a, b}$, Nikolaos Lazaridis a,c, Erasmia Vlachou a,d, Nikolaos Koukias ${ }^{a, e}$, \\ Periklis Apostolopoulos ${ }^{d}$, Alberto Murino a, Dimitrios Christodoulou ${ }^{b}$, Edward J. Despott ${ }^{a}$
}

The Royal Free Hospital and UCL Institute for Liver and Digestive Health, Hampstead, London, United Kingdom; University of Ioannina, Greece; Genesis Hospital of Thessaloniki, Greece; Army Share Funds Hospital (NIMTS), Athens, Greece; University Hospital of Patras, Greece

Abstract

The impact of small-bowel (SB) capsule endoscopy and device-assisted enteroscopy on clinical practice, since their introduction 2 decades ago, has been remarkable. These disruptive technologies have transformed the investigation and management of SB pathology and now have a firmly established place in guidelines and clinical algorithms. Furthermore, recent years have witnessed innovations, driven by the demand of new goals in the management of inflammatory bowel disease (IBD), such as mucosal healing and evolving strategies based on tight monitoring and accelerated escalation of care. These developments in SB endoscopy have also been paralleled by refinement in dedicated radiological SB imaging technologies. This updated review highlights the current state of the art and more recent innovations with a focus on their role in IBD.

Keywords Small-bowel endoscopy, enteroscopy, capsule endoscopy, inflammatory bowel disease, Crohn's disease

Ann Gastroenterol 2021; $34(x): 1-13$

${ }^{a}$ Royal Free Unit for Endoscopy, The Royal Free Hospital and UCL Institute for Liver and Digestive Health, Hampstead, London, United Kingdom (Alexandros Skamnelos, Nikolaos Lazaridis, Erasmia Vlachou, Nikolaos Koukias, Alberto Murino, Edward J. Despott); bDivision of Gastroenterology, University Hospital and Faculty of Medicine, School of Health Sciences, University of Ioannina, Ioannina, Greece (Alexandros Skamnelos, Dimitrios Christodoulou); ${ }^{\mathrm{C}}$ Genesis Hospital of Thessaloniki, Thessaloniki, Greece (Nikolaos Lazaridis); ${ }^{\mathrm{d} A r m y}$ Share Funds Hospital (NIMTS), Athens, Greece (Erasmia Vlachou, Periklis Apostolopoulos); ${ }^{\mathrm{e}}$ Department of Gastroenterology, University Hospital of Patras, Patras, Greece (Nikolaos Koukias)

Conflict of Interest: Edward J. Despott has acted as a consultant for Fujifilm, Boston Scientific and Ambu. He has also received academic grants and speaker honoraria from Fujifilm, Aquilant Endoscopy, Pentax Medical, Norgine and Olympus

Alberto Murino has acted as a consultant for Boston Scientific and GI supply. He has also received academic grants from Fujifilm, Aquilant Endoscopy, Norgine and Olympus

Alexandros Skamnelos has received a scholarship from the Hellenic Society of Gastroenterology

Correspondence to: Dr Edward John Despott, MD, FRCP, FEBGH, FASGE, MD(Res), Royal Free Unit for Endoscopy, The Royal Free Hospital and UCL Institute for Liver and Digestive Health, Pond Street, Hampstead, London NW3 2QG United Kingdom, e-mail: edespott@doctors.org.uk

Received 5 February 2021; accepted 14 April 2021;

published online 2 July 2021

DOI: https://doi.org/10.20524/aog.2021.0652

\section{Introduction}

Crohn's disease (CD) and ulcerative colitis (UC) are chronic idiopathic inflammatory bowel diseases (IBD) characterized by relapsing and remitting, immune-mediated inflammatory flare-ups, which mainly affect the gastrointestinal (GI) tract. The incidence of IBD is increasing worldwide [1-3], and although the same elusive etiological factors are implicated in the pathogenesis of both subtypes (genetic polymorphisms, gut microbiome and environmental factors), each has its own distinct clinical features [4]. Inflammation in CD is typically segmental, asymmetrical and transmural, and although CD may affect any part of the GI tract, small-bowel (SB) involvement occurs in up to $80 \%$ of cases, while in about $30 \%$ of patients, the disease is limited to the SB alone [1,2]. Most patients present with an inflammatory phenotype at diagnosis, but over time more than $50 \%$ of affected patients develop more severe, chronic complications, including strictures, fistulas, and/or abscesses, which in turn often warrant recourse to major surgery $[5,6]$. In approximately $5-15 \%$ of patients with endoscopic, radiological and histopathological evidence of chronic IBD confined to the colon, the disease does not fit the characteristic diagnostic criteria specific to either UC or $\mathrm{CD}$. In these patients, the condition is termed IBD-unclassified (IBDU). IBDU is generally considered to be a temporary diagnosis $[7,8]$, until a more definitive diagnosis of either UC or $\mathrm{CD}$ can be made. 
Patients with suspected or established CD and IBDU, therefore, require frequent investigation to evaluate or exclude SB lesions and the potential need for escalation of care. Furthermore, even in patients with established UC, SB investigation may still be warranted if the clinical picture changes or raises suspicion for an alternative diagnosis of CD [3,9].

Even with current advances, the diagnosis and management of IBD remain challenging. The establishment of new therapeutic goals, such as mucosal healing $(\mathrm{MH})$ and evolving strategies, based on tight monitoring and accelerated escalation of care, has created increasing demands and new indications for endoscopic assessment of disease activity [10,11].

Over the last 2 decades the disruptive endoscopic technologies of SB capsule endoscopy (SBCE) and deviceassisted enteroscopy (DAE) [12] have revolutionized our approach to the diagnosis and management of SB pathology. Over the years, these have been adopted into the standard of care, as demonstrated through the development of clinical guidelines by international societies such as the European Society of Gastrointestinal Endoscopy (ESGE) and the European Crohn's and Colitis Organisation (ECCO) $[13,14]$. In consequence, performance measures for clinical practice, training and competence recommendations were proposed to ensure a high standard of care and improve the quality of SB endoscopy $[15,16]$. Although these continue to evolve through novel indications, the main respective and complimentary roles of SBCE and DAE in the context of IBD are now well established. SBCE is principally a noninvasive instrument for the assessment of the SB mucosa that supports diagnosis and monitoring of disease activity. SBCE provides excellent mucosal views, while maintaining a high tolerability and safety profile in carefully selected patients $[17,18]$. DAE compliments SBCE by facilitating tissue biopsy and endotherapy, mainly endoscopic balloon dilation (EBD) of selected strictures [19-21].

The progress of SB endoscopy over the years has been mirrored by equally impressive advances in the quality and availability of dedicated SB cross-sectional imaging, including computed tomographic and magnetic resonance enterography (CTE and MRE, respectively). These complimentary endoscopic and radiological technologies have set new frontiers and now provide more accurate diagnostics, allowing for dynamic disease management and individualized patient care [22-24].

Recently, a novel modified capsule (the PillCam Crohn's ${ }^{\mathrm{m}}$; Medtronic, Dublin, Ireland), with its 2 cameras, wider viewing angle and rapid, adaptive frame rate, is able to provide panenteric mucosal CE (PECE) [25]. This minimally invasive system, designed specifically for the monitoring of disease activity in patients with suspected or established CD [25], allows for extensive evaluation of the entire GI tract and is already being incorporated into routine clinical practice [26]. Recent developments in the field of DAE include the introduction of a new double-balloon enteroscope with a wider $(3.2 \mathrm{~mm})$ working channel and higher resolution "Super CCD with CloseFocus" imaging (EN-580T, Fujifilm, Tokyo, Japan) [27], the introduction of balloon-guided enteroscopy (BGE) (Naviaid ${ }^{\text {ts }}$ AB; Pentax Medical, Tokyo, Japan) $[28,29]$ and the novel motorized spiral enteroscopy (NMSE) (PowerSpiral, Olympus Medical, Tokyo, Japan) [30].

\section{SBCE in CD}

A unique reference standard for the diagnosis of CD is still elusive, and this is therefore dependent on a corroboration of clinical, biochemical, endoscopic, radiological and histopathological findings [13]. Although ileocolonoscopy (IC) remains the primary modality for endoscopic evaluation in suspected cases [31], the role of SBCE for the detection of more proximal SB mucosal lesions is increasingly recognized. This is reflected in guidelines and consensus statements $[13,14]$.

The main advantages of SBCE are its "patient-friendly", well-tolerated, noninvasive and ambulatory nature. SBCE also provides the ability to visualize the entire SB with high diagnostic yields (DY) [32]. Detection of innocuous/incidental findings and an inability to biopsy mucosal lesions are its main limitations [33]. Capsule maneuverability, the application of artificial intelligence (AI) and more accurate localization of any identified lesions are the subjects of ongoing research $[34,35]$.

There is growing evidence in the literature to support the use of $\mathrm{AI}$ in SBCE as a valuable adjunct to reduce reading times and enhance detection of suspicious abnormalities [36]. Ding et al [37] developed a deep-learning algorithm, based on a convolutional neural network $(\mathrm{CNN})$ model to facilitate the identification and characterization of the SB pathology. The authors collected 13,426,569 images from 6970 patients who underwent SBCE over a 2-year period in 77 hospitals in China. The CNN model was initially trained to differentiate normal and pathological findings using 158,235 SBCE images recorded from 1970 procedures. It was found that the $\mathrm{CNN}$ model had a higher sensitivity for the identification of abnormalities as compared with conventional analysis by gastroenterologists in per-patient (99.9\% vs. $74.6 \%$ ) and per-lesion analysis (99.9\% vs. $76.9 \%$ ). The reading time with the CNN model was significantly shorter compared with conventional reading by gastroenterologists (5.9 vs. $96.6 \mathrm{~min}$ ) [37]. Other studies also demonstrated good performance for $\mathrm{CNN}$ models in the identification of one category of SB abnormality [38-41]. Soffer et al in their systematic review and meta-analysis related to the implementation of deep learning in CE, demonstrated that the pooled sensitivity and specificity for ulcer detection were 0.95 and 0.94 , respectively, and the pooled sensitivity and specificity for bleeding/bleeding source were 0.98 and 0.99 , respectively [42].

Another potential limitation of SBCE relates to its inability to "wash away" any luminal debris that may affect the views obtained [43]. Although ingestion of purgatives prior to SBCE for better mucosal visualization is recommended by recent guidelines, their use still remains the subject of ongoing debate $[44,45]$. Contraindications to the use of SBCE include the presence of strictures, suspected GI obstruction and swallowing disorders [46].

The main potential complication of SBCE is capsule retention, defined as persistence of the capsule within the SB for at least 2 weeks after ingestion, requiring intervention for retrieval [47]. Since CD may cause stricturing of the SB, the incidence of this complication is higher in these patients. The risk of capsule retention ranges between $0.5 \%$ in patients with suspected $C D$ and up to $13 \%$ in patients with established CD [48-55]. A more 
recent meta-analysis showed that the retention rates in patients with suspected or known IBD were approximately $4 \%$ and $8 \%$, respectively [56]. A thorough clinical history, to exclude obstructive symptoms, along with appropriate use of the patency capsule (PC) (PillCam Patency ${ }^{\mathrm{m},}$, Medtronic, Dublin, Ireland), is mandatory [57]. The PC is designed to disintegrate spontaneously within $72 \mathrm{~h}$ of retention while the presence of a radiofrequency identification tag and 5\% barium within the PC allow its detection and localization $[58,59]$. SBCE may subsequently be performed if an intact PC is excreted by $30 \mathrm{~h}$ post-ingestion. If the $\mathrm{PC}$ is excreted after $30 \mathrm{~h}$, its integrity should be carefully examined, since subsequent SBCE should only be considered if the PC is intact $[58,59]$. A retrospective study by Yadav et al suggested that the negative predictive value (NPV) for CTE, MRE and PC for capsule retention was similar, and that their role might be complimentary [60]. However, another study revealed that crosssectional imaging is significantly less accurate in the assessment of functional SB patency, frequently overestimating the risk of obstruction [61]. Other studies raise questions about the sensitivity of CTE and MRE in recognizing SB strictures [62,63]. Selective, limited exposure, non-contrast CT, rather than plain abdominal radiography, has been shown to be the best modality for reliable localization of a retained PC $[64,65]$.

\section{SBCE vs. dedicated SB imaging: MRE, CTE and small- intestinal contrast ultrasound (SICUS)}

The most recent meta-analysis by Kopylov et al, which included 10 studies comparing SBCE to MRE, demonstrated that the DY of SBCE was similar to that of MRE for detection of SB disease, in both suspected and established CD: odds ratio (OR) $1.17,95 \%$ confidence interval (CI) 0.83-1.67 [32]. These findings are in concordance with those of a previous meta-analysis by Dionysio et al [66]. Furthermore, SBCE appeared superior to MRE for the diagnosis of proximal SB CD in both established and suspected CD (OR 2.79, 95\%CI 1.2-6.48) [32]. According to another meta-analysis by Yung et al, both diagnostic modalities, SBCE (100\%, 95\%CI 91-100\%) and MRE (97\%, 95\%CI $89-$ $100 \%)$ have similar pooled sensitivity in the identification of postoperative recurrence of $\mathrm{CD}$ [67], although in a small study performed by González-Suárez SBCE was found to be significantly superior to MRE for the detection of superficial SB lesions ( $87.5 \%$ vs. $56.2 \%$, respectively, $\mathrm{P}=0.01$ ) [68].

In the same meta-analysis by Kopylov et al, the comparison between SBCE and SICUS, exhibited similar DY for suspected and established CD (OR 0.88, 95\%CI 0.51-1.53) [32]. Contrarily, the study by Yung et al demonstrated a discrepancy for pooled sensitivity between SBCE (95\%CI 91-100\%) and SICUS (95\%CI 85-92\%) for the detection of postoperative recurrence of CD [67].

The older meta-analysis by Dionisio et al also compared SBCE to CTE, and showed that overall SBCE had superior sensitivity and specificity for both suspected and established CD [66]. Considering the potential risks of repeated exposure to radiation, only a few further studies comparing these 2 modalities have since been published; these confirmed SBCE's superiority [69-72].

\section{The role of SBCE in IBD clinical practice}

\section{SBCE in suspected $C D$}

Careful mucosal assessment with SBCE has become pivotal to the diagnostic approach in patients with suspected CD (Fig. 1). The ECCO-European Society of Gastrointestinal
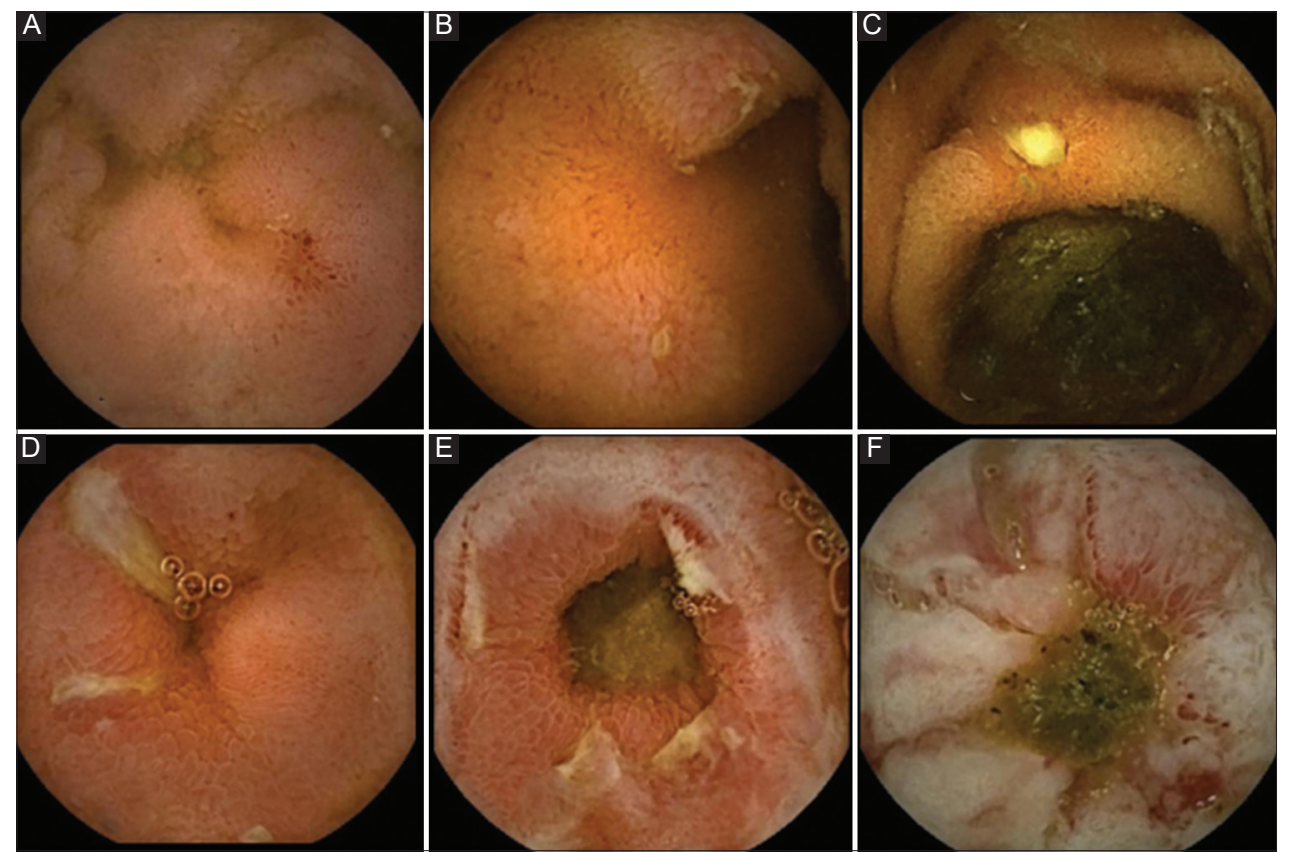

Figure 1 Inflammatory lesions of the small bowel caused by Crohn's disease, as seen on small-bowel capsule endoscopy (different patients): (A) erythema; (B) aphthous erosion; (C) aphthous ulcer; (D) linear ulcers; (E) ulcerated stricture; (F) fibrotic stricture 
and Abdominal Radiology (ESGAR) guidelines state that, in the absence of non-steroidal anti-inflammatory drug use for at least 1 month, the identification of 3 or more SB ulcers by SBCE would support a potential diagnosis of $\mathrm{CD}$ [13]. Although IC remains the investigation of first choice in patients with suspected CD, both the ESGE and the ECCOESGAR guidelines recommend the use of SBCE if IC is noncontributory and any potential stenosis has been excluded. In cases with suspected stenotic disease, cross-sectional imaging modalities should be used first $[13,14]$.

Direct correlation and the predictivevalue of biological markers with potential SBCE findings remain inconclusive [73-77]. In their meta-analysis, Kopylov et al [78] demonstrated that a cutoff fecal calprotectin (FC) level of $50 \mu \mathrm{g} / \mathrm{g}$ could be a predictor of positive findings on SBCE (sensitivity 0.83 , specificity 0.53 ). Egea-Valenzuela et al reported better results (75\% sensitivity and $67 \%$ specificity) with a higher cutoff value for FC (>100 $\mu \mathrm{g} / \mathrm{g})$ [79]. This was echoed by another study with a threshold value of $>95 \mu \mathrm{g} / \mathrm{g}[80]$ (77\% sensitivity and $60 \%$ specificity). However, the contention lies in the fact that some other studies have failed to confirm any corroborative relationship between FC concentrations and SBCE findings [81,82]. C-reactive protein (CRP) levels were also found to have no correlation with SBCE activity scores $[74,83]$. SBCE has also been proven to be a valuable diagnostic modality in patients with unexplained fistulas and suspected CD in the context of a negative IC [13].

\section{SBCE in established CD}

The management of IBD remains challenging, even in the modern era of advanced biological therapy. The discrepancy between symptoms and endoscopic findings, and the critical need of detecting worsening disease activity at an early stage, have established new goals in management [10]. MH and evolving strategies based on tight monitoring and accelerated escalation of care ("treat-to-target"), have increased referrals for endoscopic assessment of disease activity [10,84-88].

The need for quantification of inflammatory activity by validated systems led to the development of scoring modalities, including the Lewis score (Table 1) [89] and the CE CD Activity Index (CECDAI) (Table 2) [90]. The CECDAI estimates inflammatory activity, disease extent, and the presence of any stricturing, with localization in relation with the transit time of the capsule [90]. Similarly, the Lewis score reports on the presence and distribution of villous edema, ulceration, and stenosis [89]. These scores are designed to allow for a more objective estimation of SB disease activity and thus more standardized reporting.

In patients with established CD, the ESGE suggests that further evaluation of disease extent and location should be initially performed with cross-sectional imaging, since this may exclude transmural and extraluminal disease [14]. Should cross-sectional imaging be unremarkable or non-diagnostic, disease mapping with the use of SBCE is recommended; if any potential findings are deemed to alter disease management [14]. The ECCO-ESGAR guidelines additionally
Table 1 Lewis score

\begin{tabular}{llll}
\hline $\begin{array}{l}\text { Parameters } \\
\text { Number }\end{array}$ & \multicolumn{1}{l}{$\begin{array}{l}\text { Longitudinal } \\
\text { extent }{ }^{1}\end{array}$} & Descriptors \\
\hline $\begin{array}{l}\text { Villous } \\
\text { appearance } \\
\text { (worst- } \\
\text { affected } \\
\text { tertile) }\end{array}$ & $\begin{array}{l}\text { Normal: } 0 \\
\text { Edematous: } 1\end{array}$ & $\begin{array}{l}\text { Short segment: } 8 \\
\text { Long segment: } 12 \\
\text { Whole tertile: } 20\end{array}$ & $\begin{array}{l}\text { Single: } 1 \\
\text { Patchy: } 14\end{array}$ \\
Diffuse: 17
\end{tabular}

Table 2 Capsule endoscopy Crohn's disease activity index scoring system

\begin{tabular}{ll}
\hline A. Inflammation & $\begin{array}{l}0=\text { none } \\
1=\end{array}$ \\
& denudation \\
2 & $=$ severe edema/hyperemia/denudation \\
3 & $=$ bleeding, exudate, aphthae, erosion, small \\
& ulcer $(<0.5 \mathrm{~cm})$ \\
4 & $=$ moderate ulcer $(0.5-2 \mathrm{~cm})$, pseudopolyp \\
5 & $=$ large ulcer $(>2 \mathrm{~cm})$
\end{tabular}

highlight the role of SBCE for the assessment of $\mathrm{MH}$ and response to medical therapy [13].

A recent prospective multicenter study demonstrated that there is concordance between SBCE and IC scores 
for the evaluation of $\mathrm{MH}$. Both Lewis score and CE CD Endoscopic Index of Severity were correlated with the Simple Endoscopic Score for $\mathrm{CD}(\mathrm{P}<0.001, \rho=0.59$, and $\mathrm{P}=0.002$, $\rho=0.48$, respectively). However, within the same study, a poor correlation was shown between endoscopic scores and clinical parameters (Crohn's Disease Activity Index, CRP, erythrocyte sedimentation rate, or FC) [75].

Current recommendations recognize the superior accuracy of SBCE vis-à-vis CTE and MRE for the identification of mucosal lesions within the proximal SB [14,70,91], and its ability to detect proximal SB lesions in up to $50 \%$ of patients, with disease previously thought to be confined to the distal ileum [92]. This is of clinical importance, since the presence of $\mathrm{CD}$ activity within the proximal $\mathrm{SB}$ has been shown to be correlated with phenotype severity, warranting earlier escalation to more intensive management $[93,94]$.

In the context of suspected postoperative ileocolonic disease recurrence, the ESGE recommends that SBCE is indicated if there has been inadequate assessment by IC [14]. The ECCO-ESGAR guidelines suggest that FC, SICUS, MRE and SBCE can all be considered as noninvasive alternatives to detect postoperative recurrence [13]. A recent systematic review demonstrated that SBCE can detect postoperative recurrence to a similar extent as IC, and proximal SB lesions that are beyond the reach of a colonoscope in over $50 \%$ of patients [95]. PC use should always be considered before SBCE in this setting in order to rule out any postoperative stricturing, thus mitigating the risk of potential capsule retention.

\section{SBCE in IBDU/UC}

SBCE may be used to evaluate any suspected SB inflammatory activity in patients with IBDU. Monteiro et al demonstrated that findings on SBCE in keeping with CD were revealed in $25 \%$ of patients with IBDU, with a positive predictive value of $100 \%$ and a high NPV (94\%) [96]. In another study performed by Min et al, the use of SBCE helped to reclassify a diagnosis of UC or IBDU to CD in 50\% of patients [97]. SBCE identified SB lesions and consequently helped to change the diagnosis to $\mathrm{CD}$ in up to $65.2 \%$ of patients originally diagnosed with post-surgical pouchitis [95]. Although negative findings on SBCE in patients with IBDU do not rule out a potential diagnosis of CD [98-100], current recommendations recognize the usefulness of SBCE in the reclassification of IBDU and its potential utility in the accelerated management of the underlying disease $[13,14]$.

\section{Pan-enteric mucosal capsule endoscopy (PECE)}

PECE (PillCam Crohn's ${ }^{\text {na }}$; Medtronic, Dublin, Ireland) is a noninvasive imaging technique recently approved as an imaging modality for the monitoring of CD activity (Table 3) [101]. This is a novel capsule system, based on an updated version of the twincamera colon capsule (second generation colon capsule, PillCam $\mathrm{COLON}^{\mathrm{sx}}$, Medtronic, Dublin, Ireland) [101], which allows for mucosal evaluation of both the small and large bowel. The PECE
Table 3 PillCam Crohn's disease capsule score

\begin{tabular}{|c|c|}
\hline $\begin{array}{l}\text { A. Most } \\
\text { common } \\
\text { lesion }\end{array}$ & $\begin{array}{l}0=\text { none } \\
1=\text { mild } \\
2=\text { moderate } \\
3=\text { severe }\end{array}$ \\
\hline $\begin{array}{l}\text { B. Most } \\
\text { severe } \\
\text { lesion }\end{array}$ & $\begin{array}{l}0=\text { none } \\
1=\text { mild } \\
2=\text { moderate } \\
3=\text { severe }\end{array}$ \\
\hline $\begin{array}{l}\text { C. Extent of } \\
\text { disease }\end{array}$ & $\begin{array}{l}0=\text { none } \\
1=10-30 \% \\
2=30-60 \% \\
3=60-100 \%\end{array}$ \\
\hline D. Stricture & $\begin{array}{l}0=\text { none } \\
1=1 \text { traversed } \\
2=>1 \text { traversed } \\
3=\text { retention }\end{array}$ \\
\hline $\begin{array}{l}\text { Score } \\
\text { calculation }\end{array}$ & $\begin{array}{l}\text { Segmental score }=((\mathrm{A}+\mathrm{B}) \times \mathrm{C})+\mathrm{D} \\
\text { Small bowel score is the sum of } 3 \text { tertiles }(\mathrm{SB} 1+\mathrm{SB} 2 \\
+\mathrm{SB} 3) \\
\text { Panenteric score is the sum of SC score plus left and } \\
\text { right colon scores }(\mathrm{SB} 1+\mathrm{SB} 2+\mathrm{SB} 3+\mathrm{RC}+\mathrm{LC})\end{array}$ \\
\hline Comments & $\begin{array}{l}\text { Novel score and needs further validation } \\
\text { PillCam Crohn's capsule approximates anatomical } \\
\text { small bowel segmentation }\end{array}$ \\
\hline
\end{tabular}

Panenteric Crohn's capsule scoring system (adapted from Eliakim et al, United European Gastroenterology Journal, 2020 [101]

combines a long-lasting battery (up to $14 \mathrm{~h}$ battery life) with wideangle cameras ( $336^{\circ}$ view), together with an adaptive frame rate, to provide excellent visualization of the entire GI tract during a single procedure $[101,102]$. Also, the novel software (Rapid $9^{\mathrm{m}}$, Medtronic, Dublin, Ireland) allows estimated localization of any mucosal lesions and the scoring of disease extent and activity $[101,103]$. The main indications of PECE in established CD include disease classification, monitoring for $\mathrm{MH}$, and evaluation of unexplained symptoms and anemia [101]. PECE shows higher sensitivity than IC and MRE for the detection of active CD in the proximal SB, as well as higher specificity than MRE [26]. It may therefore allow for a more accurate evaluation of prognosis and guidance for escalation or de-escalation of treatment [103]. Other studies confirm the high technical and diagnostic performances of PECE for both initial diagnosis and monitoring of established IBD $[25,102]$. PECE promises to be a low-risk and cost-effective investigation, which may reduce the number and invasiveness of investigations required to establish effective and timely care, with potential earlier recovery $[26,104]$. According to ESGE recommendations, a patency capsule should be offered to all $\mathrm{CD}$ patients prior to SBCE to ensure functional patency of the SB, irrespective of previous unremarkable cross-sectional imaging [14]. If the correct protocol is followed, it has been shown to be very safe, with a very low risk of capsule retention [25,104].

\section{DAE in CD}

DAE allows direct and potentially complete visualization of the SB through both the oral (anterograde) and/or the anal (retrograde) route $[12,14]$. Since its introduction in 
2001 [12], DAE has superseded push enteroscopy (PE) and intraoperative enteroscopy (IOE) as the preferred modality for flexible endoscopy of the SB [14]. PE only allows examination of a limited part of the proximal SB, while IOE is an inherently invasive procedure, with risks of significant morbidity and mortality [105]. Nevertheless, both still have a limited role to play, especially in cases where DAE is not available or where surgical management cannot be avoided [14,106].

DAE allows deep for intubation of the SB, usually facilitated by balloon(s), and overtube. DAE includes double and singleballoon enteroscopy (DBE and SBE, respectively), BGE and the former manual spiral enteroscopy, recently relaunched as NMSE. BGE is assisted by an on-demand, through-the-scope balloon working as an anchor into the SB [28]. DBE and SBE use a stabilizing overtube with incorporated distal balloon. This is used in conjunction with a balloon attached to the tip of the enteroscope in the case of DBE $[12,107]$. Both DBE and SBE achieve deep SB intubation with a combination of insertion and retraction of the enteroscope while the inflated balloons gently grip the intestine, allowing SB manipulation. This "push-and-pull" technique leads to progressive shortening of the SB and pleating onto the overtube. The lack of a second balloon in SBE is countered by the "hook-and-suck" technique that entails suction of the SB mucosa and tip-of-the-scope angulation $[108,109]$. SE requires an overtube equipped with a spiral-shaped silicone elevation; in the case of the recently introduced NMSE, this is connected to an electric motor that powers its rotation. Clockwise and anticlockwise rotation of the spiral overtube pleats the SB, allowing for advancement and withdrawal of the enteroscope into and out of the SB, respectively $[110,111]$. The safety and efficacy of NMSE are the subject of ongoing clinical studies [112,113].

The efficacy and DY of DAE have been addressed through several studies $[28,111,114-122]$. Since it was the first form of DAE to be introduced into clinical practice, most of the evidence relates to $\mathrm{DBE}[12,117,118,120-122]$. Comparisons between DBE and SBE enteroscopy have varied and interchangeable results regarding DY, depth of insertion and adverse events, while SE appeared to have the advantage of a shorter SB insertion time [123-126]. The ESGE and ECCOESGAR recommendations suggest that DAE techniques have similar efficiency and safety considerations and can be applied according to local availability and expertise [9,13-14,44,127]. Studies in pediatric patients support the safe use of balloonassisted enteroscopy (BAE) in children, when clinically indicated [128-133]. Although the safety profile of NMSE requires further evaluation in routine clinical practice, it has been shown to be contraindicated in pediatric patients [134].

Excluding NMSE, DAE has been associated with an overall intraprocedural complication rate of $0.72 \%$; these complications include bleeding $(0.07 \%)$, perforation $(0.2 \%)$, and pancreatitis $(0.3 \%)$ [135]. Potential adverse events relating to deep sedation and anesthesia should also be considered, and to mitigate these, preprocedural assessment by an anesthetist is advised. The complication rate appears to be relatively higher in patients with IBD and is increased when endotherapy is applied [136,137].
While DAE is not considered to be a first-line diagnostic tool for $\mathrm{CD}$, it may facilitate diagnosis in cases with non-diagnostic IC and suspicious radiological and/or SBCE findings [9,14,127] (Fig. 2). DAE may allow direct inspection of the entire SB and provide histopathological samples to corroborate a final diagnosis. Additionally, DAE is useful when patients with established CD require endotherapy. Even though enteroscopy is a relatively safe procedure, careful planning is needed, as $\mathrm{DAE}$ is more invasive in its nature, with technical challenges and possible adverse events $[14,108,109]$.

DAE can provide additional corroborative findings, should initial, less invasive investigations prove inconclusive. The DY of DAE varies significantly; initial studies (albeit including small numbers of patients) reported a DY for DBE that ranged from $22-60 \%[120,121]$. More recent studies reported a DY of $79 \%$ in cases with suspected CD, depending on the presence or absence of endoscopic findings. Biopsy sampling during DAE helped to establish a diagnosis of CD in up to $40 \%$ of cases [117]. DBE facilitated a final diagnosis of SB CD in $67 \%$ of cases $(12 / 18)$ with histopathological confirmation, when patient selection followed radiological and SBCE investigation [122]. A larger retrospective cohort of $122 \mathrm{DBE}$ procedures in 100 patients reported endoscopic findings indicative of CD in $60 \%$ of cases, even though histopathological confirmation was significantly lower (38\%) [118]. A smaller study from Italy showed a DY of $39 \%$ when SBE was performed in 13 patients suspected of having CD [119]. DBE and SBE performance has been further evaluated during the last decade, and their efficacy and DY are comparable [125]. Although large studies evaluating the role of NMSE in the diagnosis of CD are still lacking, a recently published experience from a single center showed that it helped to establish a diagnosis of CD in 16 of 25 patients (64\%) in whom CD was suspected [111].

DBE can also help achieve a definitive diagnosis of CD in a pediatric setting. This was shown in another recent study, in
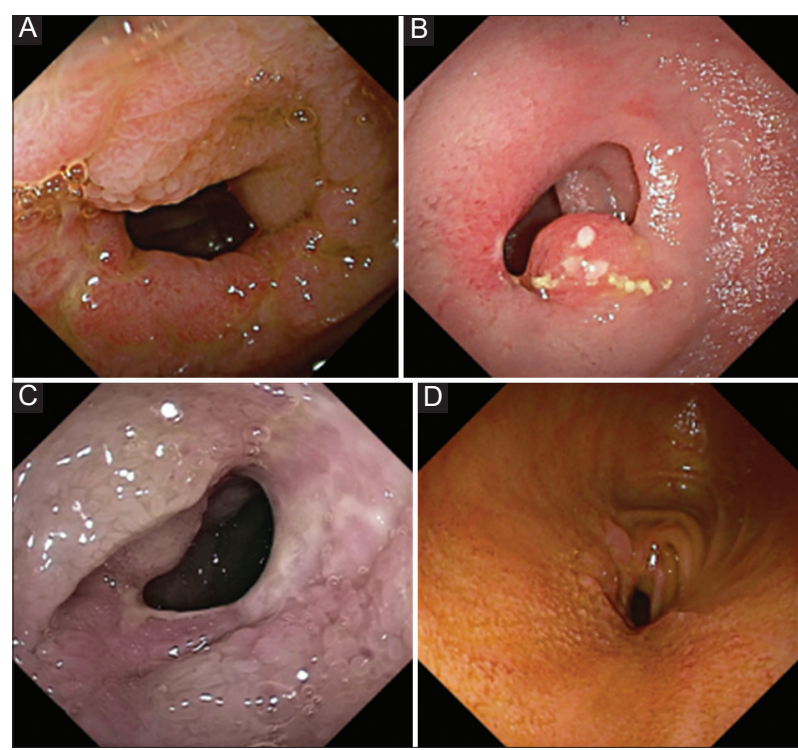

Figure 2 (A,B,C) Fibrotic strictures of the small bowel (SB) as seen on double-balloon enteroscopy. (D) Fibrotic stricture of the SB with prestenotic pseudosacculation 
which 16 of 61 children (26\%) with non-specific symptoms were diagnosed with $\mathrm{CD}$. Children with abdominal pain, diarrhea and/or SB obstruction had a 30\% confirmation of CD after tissue sampling [128]. Similarly, SBE identified the presence of endoscopic findings in $60 \%$ of any suspected IBD cases and guided a diagnosis of CD in 8 of 14 (57\%) pediatric patients [129].

The diagnostic role of DAE in suspected CD should be reserved for cases where a definitive diagnosis remains elusive, despite the use of less invasive imaging (CTE, MRE and SBCE). Nonetheless, its role remains important in the management of patients with established CD $[14,127]$. DAE allows for the direct evaluation of disease activity and its extent, it facilitates direct monitoring of $\mathrm{MH}$ and response to therapy, the retrieval of retained SB capsules and EBD of SB strictures.

$\mathrm{EBD}$ is the main endotherapeutic intervention for patients with SB CD (Fig. 3). EBD is less invasive than surgical alternatives and repeat dilations can be performed, if and when clinically indicated (Fig. 4). The use of fluoroscopy is advised when EBD is performed [14,108]; treatment algorithms have been proposed [109] and novel dedicated accessories, such as the calibrated small-caliber tip hood, have been introduced, to improve the quality and safety of the procedure [138]. DAE-facilitated EBD is usually performed using a transparent through-the-scope balloon dilator. This is gradually inflated with water ( \pm contrast), under direct endoscopic and fluoroscopic visualization.

Numerous reports have documented the efficacy and safety of EBD in carefully selected cases [19,139-142]. EBD can improve symptoms and delay or obviate recourse to surgery [108]. According to international guidelines, SB strictures suitable for endoscopic dilation are those $\leq 5 \mathrm{~cm}$ in length with proximal dilation and without active inflammation, deep ulcers, abscesses and/or fistulas. Sharp-angulation of the SB is an additional unfavorable factor $[14,19,44,108,143]$ that may increase the risk of complications. The optimal DAE insertion route should be guided by SB imaging prior to the procedure. To date, the majority of studies relating to EBD used BAE to apply endotherapy $[19,136,137,139-141,144-147]$. Although in a recent study, NMSE facilitated dilation of 3 strictures, along with retrieval of a retained capsule, without any adverse events, additional studies are warranted to further evaluate the safety and effectiveness of this recently introduced modality [134].

The first large Japanese studies on EBD success and safety documented encouraging results, regardless of the type of
BAE used. DBE-facilitated EBD was applied successfully in 52 symptomatic patients, with a short-term success rate of $92.3 \%$ and a total complication rate of $9.2 \%$ (perforation rate: $1.5 \%)$. In total, $26.2 \%$ of the study population needed surgical management and almost half of the previously dilated patients needed an additional EBD during the next 24 months [136]. Similarly, another study reported on SBE-facilitated EBD in 37 patients. In this study, there was a $76.2 \%$ reduction in the severity of obstructive symptoms and no major adverse event. Repeated DAE with additional EBD was deemed necessary in $48.6 \%(18 / 37)$ of the patients; 5 of these required surgical intervention [137]. These results were reflected in a large pooled analysis with 3213 EBD procedures in 1463 patients with primary and anastomotic, predominantly ileal strictures. Technical success was achieved in $90 \%$ and symptomatic relief was achieved in $80 \%$; the complication rate was $2.8 \%$. Nevertheless, almost $75 \%$ of the patients needed repeat dilation and $43 \%$ required surgery within 24 months [142]. A systematic review of SB dilation facilitated by DBE reported an $80 \%$ longterm success rate, with a complication rate of $2.6 \%$ per dilation and $4.8 \%$ per patient. After an average 32 months of follow up, only $17 \%$ of patients had required surgery; however, $46 \%$ required additional EBD [148].

The first prospective multi-center study of BAE-facilitated EBD for patients with SB strictures relating to CD was performed in Japan in 2018 and included 95 patients [139]. Technical success of EBD was reported in 89 (93.7\%) patients, and $66(69.5 \%)$ patients reported a 4-week, short-term improvement in symptoms. Although the overall complication rate was $5 \%$, there were no perforations and only 1 patient needed surgical intervention within the follow-up period [139]. The apparent trend is that long-term EBD outcomes are improving as experience, enteroscopes and accessories are further refined [140,149]. Among 85 patients with SB strictures due to CD, who underwent a total of 473 successful EBDs, the overall surgery-free rate was $87.3 \%$ after 1 year, $78.1 \%$ after 3 years and $74.2 \%$ after 5 years. In total 21 patients (24.7\%) eventually needed surgical intervention. Adverse events were reported in $1 \%$ of all procedures, with a $0.8 \%$ perforation risk per dilation and a $4.7 \%$ risk per patient [140]. In a smaller cohort of 26 patients with $\mathrm{CD}$, who all achieved short-term improvement, the long-term outcomes were also encouraging, with a cumulative surgery-free rate of $90.3 \%$ at both 2 and 3 years after initial dilation. Only 2 patients (7.7\%)
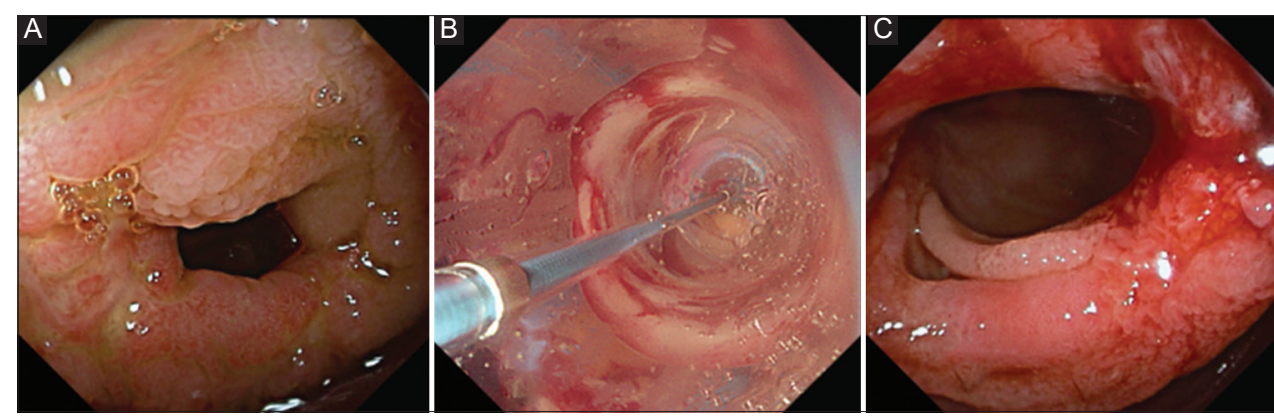

Figure 3 (A) Fibrotic stricture of the small bowel, as seen on double-balloon enteroscopy (DBE). (B) Through-the-balloon view at endoscopic balloon dilation (EBD) of a small bowel fibrotic stricture, as seen on DBE. (C) Post-EBD of the same stricture, as seen on DBE 


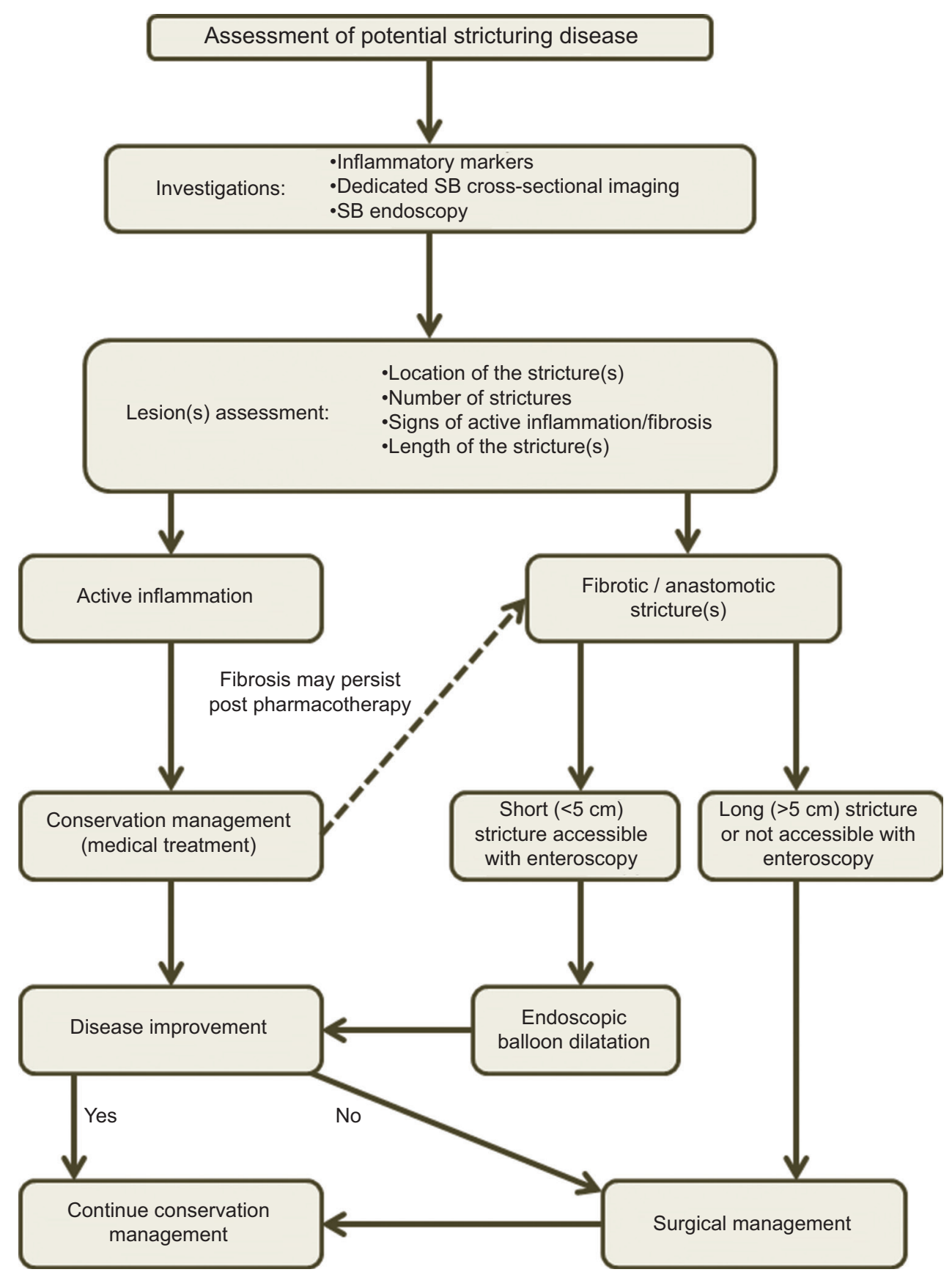

Figure 4 Algorithm for the management of small-bowel (SB) strictures caused by Crohn's disease [109]

needed surgery during this period of follow-up. These results were achieved with repeat EBD in $42 \%$ of patients; thus, the cumulative redilation-free rate was $47.8 \%$ and $31.9 \%$ at 2 and 3 years post initial EBD, respectively [149]. Lastly, a multicenter retrospective study included 305 patients, 100 of whom underwent successful EBD facilitated by BAE. After initial dilation, the cumulative surgery-free rate was $93.8 \%, 72.8 \%$ and $62.9 \%$ after 1,5 and 10 years, respectively; all rates were higher compared with the surgery-free rate of the cohort. Postprocedural complications were reported in 3 cases, 1 of which was a perforation requiring surgical management (1\%).
The authors reported a less satisfactory response to EBD when patients were active smokers [141].

According to long-term outcomes, there is an evident need for frequent repeat $\mathrm{EBD}$ due to recurrence of symptoms $[139,140]$. Repeat DAE and prophylactic EBD may be required to prolong the surgical-free period and for the prevention of symptom recurrence [148]. Pre-stenotic dilation, active disease and an Asian heritage are some factors associated with a greater recourse to surgery in the multivariate analysis of a large systematic review [142]. Similarly, the main risk factor regarding any intervention (endotherapy or surgery), 
was the presence of active disease, while medication with antitumor necrosis factor reduced the need for reintervention. Patients with short fibrotic strictures $(\leq 5 \mathrm{~cm})$ and without active inflammatory disease were shown to be ideal candidates for dilation with a low risk of relapse [142]. Thus, a longer time interval between initial EBD and repeat procedure has been associated with lower surgical risk. Interestingly, any association between the presence of multiple strictures and a greater risk for surgery remains unproven [141].

Since the introduction of DBE in 2001 [12], DAE has played an important role in the diagnosis and management of CD. Apart from assistance in the differential diagnosis of $\mathrm{CD}$ in patients with noncontributory investigations, the main advantage of DAE is that it enables endotherapy. DAE facilitates the retrieval of foreign bodies (mainly retained capsules) and EBD, with high success rates and a low frequency of intra- and postprocedural complications in expert hands. EBD can be repeated, depending on the clinical presentation, and may postpone or obviate the need for intestinal resection, improving the patient's overall quality of life.

\section{Concluding remarks}

Since their introduction 2 decades ago, both SBCE and DAE have established key roles in the diagnosis and management of IBD of the SB; a complementary role reflected in current guidelines and clinical algorithms. Also complemented by further refinement in dedicated radiological cross-sectional imaging, the recent developments seen in SBCE now allow for panenteric, minimally invasive monitoring of disease activity with objective assessment of response to treatment, facilitating the goal of personalized medical therapy. The last 2 decades of experience with DAE have also allowed the accumulation of broader expertise and evidence to support the safe and effective use of EBD as a minimally invasive alternative to surgery, in selected patients with stricturing disease of the $\mathrm{SB}$. At the same time, SB endoscopy has evolved from a novel concept into an indispensable part of clinical practice, with specific prerequisites and quality measures ensuring optimal care and patient safety.

\section{References}

1. Ng SC, Shi HY, Hamidi N, et al. Worldwide incidence and prevalence of inflammatory bowel disease in the $21^{\text {st }}$ century: a systematic review of population-based studies. Lancet 2017;390:2769-2778.

2. Torres J, Mehandru S, Colombel JF, Peyrin-Biroulet L. Crohn's disease. Lancet 2017;389:1741-1755.

3. Ungaro R, Mehandru S, Allen PB, Peyrin-Biroulet L, Colombel JF. Ulcerative colitis. Lancet 2017;389:1756-1770.

4. Danese S, Fiocchi C. Etiopathogenesis of inflammatory bowel diseases. World J Gastroenterol 2006;12:4807-4812.

5. Peyrin-Biroulet L, Loftus EV Jr, Colombel JF, Sandborn WJ. The natural history of adult Crohn's disease in population-based cohorts. Am J Gastroenterol 2010;105:289-297.

6. Thia KT, Sandborn WJ, Harmsen WS, Zinsmeister AR, Loftus EV Jr.
Risk factors associated with progression to intestinal complications of Crohn's disease in a population-based cohort. Gastroenterology 2010;139:1147-1155.

7. Tremaine WJ. Diagnosis and treatment of indeterminate colitis. Gastroenterol Hepatol (N Y) 2011;7:826-828.

8. Zhou N, Chen WX, Chen SH, Xu CF, Li YM. Inflammatory bowel disease unclassified. J Zhejiang Univ Sci B 2011;12:280-286.

9. Bourreille A, Ignjatovic A, Aabakken L, et al; World Organisation of Digestive Endoscopy (OMED) and the European Crohn's and Colitis Organisation (ECCO). Role of small-bowel endoscopy in the management of patients with inflammatory bowel disease: an international OMED-ECCO consensus. Endoscopy 2009;41: 618-637.

10. Agrawal M, Colombel JF. Treat-to-target in inflammatory bowel diseases, what is the target and how do we treat? Gastrointest Endosc Clin N Am 2019;29:421-436.

11. Peyrin-Biroulet L, Sandborn W, Sands BE, et al. Selecting therapeutic targets in inflammatory bowel disease (STRIDE): determining therapeutic goals for treat-to-target. Am J Gastroenterol 2015;110:1324-1338.

12. Yamamoto H, Sekine Y, Sato Y, et al. Total enteroscopy with a nonsurgical steerable double-balloon method. Gastrointest Endosc 2001;53:216-220.

13. Maaser C, Sturm A, Vavricka SR, et al; European Crohn's and Colitis Organisation [ECCO] and the European Society of Gastrointestinal and Abdominal Radiology [ESGAR]. ECCOESGAR Guideline for Diagnostic Assessment in IBD Part 1: Initial diagnosis, monitoring of known IBD, detection of complications. J Crohns Colitis 2019;13:144-164.

14. Pennazio M, Spada C, Eliakim R, et al. Small-bowel capsule endoscopy and device-assisted enteroscopy for diagnosis and treatment of small-bowel disorders: European Society of Gastrointestinal Endoscopy (ESGE) Clinical Guideline. Endoscopy 2015;47:352-376.

15. Sidhu R, Chetcuti Zammit S, Baltes P, et al. Curriculum for smallbowel capsule endoscopy and device-assisted enteroscopy training in Europe: European Society of Gastrointestinal Endoscopy (ESGE) Position Statement. Endoscopy 2020;52:669-686.

16. Spada C, McNamara D, Despott EJ, et al. Performance measures for small-bowel endoscopy: a European Society of Gastrointestinal Endoscopy (ESGE) Quality Improvement Initiative. Endoscopy 2019;51:574-598.

17. Luján-Sanchis M, Sanchis-Artero L, Larrey-Ruiz L, et al. Current role of capsule endoscopy in Crohn's disease. World J Gastrointest Endosc 2016;8:572-583.

18. Goran L, Negreanu AM, Stemate A, Negreanu L. Capsule endoscopy: current status and role in Crohn's disease. World J Gastrointest Endosc 2018;10:184-192.

19. Despott EJ, Gupta A, Burling D, et al. Effective dilation of smallbowel strictures by double-balloon enteroscopy in patients with symptomatic Crohn's disease (with video). Gastrointest Endosc 2009;70:1030-1036.

20. Sunada K, Yamamoto $\mathrm{H}$, Kita $\mathrm{H}$, et al. Clinical outcomes of enteroscopy using the double-balloon method for strictures of the small intestine. World J Gastroenterol 2005;11:1087-1089.

21. Yamamoto H, Yano T, Kita H, Sunada K, Ido K, Sugano K. New system of double-balloon enteroscopy for diagnosis and treatment of small intestinal disorders. Gastroenterology 2003;125:1556; author reply 1556-1557.

22. Qiu Y, Mao R, Chen BL, et al. Systematic review with meta-analysis: magnetic resonance enterography vs. computed tomography enterography for evaluating disease activity in small bowel Crohn's disease. Aliment Pharmacol Ther 2014;40:134-146.

23. Rimola J, Planell N, Rodríguez S, et al. Characterization of inflammation and fibrosis in Crohn's disease lesions by magnetic 
resonance imaging. Am J Gastroenterol 2015;110:432-440.

24. Higgins PD. Measurement of fibrosis in Crohn's disease strictures with imaging and blood biomarkers to inform clinical decisions. Dig Dis 2017;35:32-37.

25. Eliakim R, Spada C, Lapidus A, et al. Evaluation of a new panenteric video capsule endoscopy system in patients with suspected or established inflammatory bowel disease - feasibility study. Endosc Int Open 2018;6:E1235-E1246.

26. Bruining DH, Oliva S, Fleisher MR, Fischer M, Fletcher JG; BLINK study group. Panenteric capsule endoscopy versus ileocolonoscopy plus magnetic resonance enterography in Crohn's disease: a multicentre, prospective study. BMJ Open Gastroenterol 2020;7:e000365.

27. Nakamura M, Yano T, Esaki M, et al. Novel ultrathin doubleballoon endoscopy for the diagnosis of small-bowel diseases: a multicenter nonrandomized study. Endoscopy 2020 Sep 9 [Online ahead of print]. doi: 10.1055/a-1243-0226

28. Kumbhari V, Storm AC, Khashab MA, et al. Deep enteroscopy with standard endoscopes using a novel through-the-scope balloon. Endoscopy 2014;46:685-689.

29. Tontini GE, Grauer M, Akin H, et al. Extensive small-bowel diverticulosis identified with the newly introduced On Demand Enteroscopy system. Endoscopy 2013;45 Suppl 2 UCTN: E350-E351.

30. Neuhaus H, Beyna T, Schneider M, Devière J. Novel motorized spiral enteroscopy: first clinical case. VideoGIE 2016;1:32-33.

31. Van Assche G, Dignass A, Panes J, et al; European Crohn's and Colitis Organisation (ECCO). The second European evidencebased Consensus on the diagnosis and management of Crohn's disease: Definitions and diagnosis. J Crohns Colitis 2010;4:7-27.

32. Kopylov U, Yung DE, Engel T, et al. Diagnostic yield of capsule endoscopy versus magnetic resonance enterography and small bowel contrast ultrasound in the evaluation of small bowel Crohn's disease: systematic review and meta-analysis. Dig Liver Dis 2017;49:854-863.

33. Leighton JA. The role of endoscopic imaging of the small bowel in clinical practice. Am J Gastroenterol 2011;106:27-36.

34. Postgate A, Despott E, Burling D, et al. Significant small-bowel lesions detected by alternative diagnostic modalities after negative capsule endoscopy. Gastrointest Endosc 2008;68:1209-1214.

35. Ross A, Mehdizadeh S, Tokar J, et al. Double balloon enteroscopy detects small bowel mass lesions missed by capsule endoscopy. Dig Dis Sci 2008;53:2140-2143.

36. Le Berre C, Sandborn WJ, Aridhi S, et al. Application of artificial intelligence to gastroenterology and hepatology. Gastroenterology 2020;158:76-94.

37. Ding Z, Shi H, Zhang H, et al. Gastroenterologist-level identification of small-bowel diseases and normal variants by capsule endoscopy using a deep-learning model. Gastroenterology 2019;157:10441054.

38. Aoki T, Yamada A, Aoyama K, et al. Automatic detection of erosions and ulcerations in wireless capsule endoscopy images based on a deep convolutional neural network. Gastrointest Endosc 2019;89:357-363.

39. Aoki T, Yamada A, Aoyama K, et al. Clinical usefulness of a deep learning-based system as the first screening on small-bowel capsule endoscopy reading. Dig Endosc 2020;32:585-591.

40. Klang E, Barash Y, Margalit RY, et al. Deep learning algorithms for automated detection of Crohn's disease ulcers by video capsule endoscopy. Gastrointest Endosc 2020;91:606-613.

41. Saito H, Aoki T, Aoyama K, et al. Automatic detection and classification of protruding lesions in wireless capsule endoscopy images based on a deep convolutional neural network. Gastrointest Endosc 2020;92:144-151.

42. Soffer S, Klang E, Shimon O, et al. Deep learning for wireless capsule endoscopy: a systematic review and meta-analysis. Gastrointest Endosc 2020;92:831-839.

43. Song HJ, Moon JS, Shim KN. Optimal bowel preparation for video capsule endoscopy. Gastroenterol Res Pract 2016;2016:6802810.

44. Rondonotti E, Spada C, Adler S, et al. Small-bowel capsule endoscopy and device-assisted enteroscopy for diagnosis and treatment of small-bowel disorders: European Society of Gastrointestinal Endoscopy (ESGE) Technical Review. Endoscopy 2018;50:423-446.

45. Gkolfakis P, Tziatzios G, Dimitriadis GD, Triantafyllou K. Metaanalysis of randomized controlled trials challenging the usefulness of purgative preparation before small-bowel video capsule endoscopy. Endoscopy 2018;50:671-683.

46. Bandorski D, Kurniawan N, Baltes P, et al. Contraindications for video capsule endoscopy. World J Gastroenterol 2016;22:9898-9908.

47. Cave D, Legnani P, de Franchis R, Lewis BS; ICCE. ICCE consensus for capsule retention. Endoscopy 2005;37:1065-1067.

48. Kopylov U, Nemeth A, Koulaouzidis A, et al. Small bowel capsule endoscopy in the management of established Crohn's disease: clinical impact, safety, and correlation with inflammatory biomarkers. Inflamm Bowel Dis 2015;21:93-100.

49. Nemeth A, Kopylov U, Koulaouzidis A, et al. Use of patency capsule in patients with established Crohn's disease. Endoscopy 2016;48:373-379.

50. Cheifetz AS, Kornbluth AA, Legnani P, et al. The risk of retention of the capsule endoscope in patients with known or suspected Crohn's disease. Am J Gastroenterol 2006;101:2218-2222.

51. Cohen SA, Gralnek IM, Ephrath H, Stallworth A, Wakhisi T. The use of a patency capsule in pediatric Crohn's disease: a prospective evaluation. Dig Dis Sci 2011;56:860-865.

52. Dussault C, Gower-Rousseau C, Salleron J, et al. Small bowel capsule endoscopy for management of Crohn's disease: a retrospective tertiary care centre experience. Dig Liver Dis 2013;45:558-561.

53. Caunedo-Alvarez A, Romero-Vazquez J, Herrerias-Gutierrez JM. Patency and Agile capsules. World J Gastroenterol 2008;14:5269-5273.

54. Höög CM, Bark L, Arkani J, Gorsetman J, Broström O, Sjöqvist U. Capsule retentions and incomplete capsule endoscopy examinations: an analysis of 2300 examinations. Gastroenterol Res Pract 2012;2012:518718.

55. Nemeth A, Wurm Johansson G, Nielsen J, Thorlacius H, Toth E. Capsule retention related to small bowel capsule endoscopy: a large European single-center 10-year clinical experience. United European Gastroeneterol J 2017;5:677-686.

56. Rezapour M, Amadi C, Gerson LB. Retention associated with video capsule endoscopy: systematic review and meta-analysis. Gastrointest Endosc 2017;85:1157-1168.

57. Mitselos IV, Katsanos K, Tsianos EV, Eliakim R, Christodoulou D. Clinical use of patency capsule: a comprehensive review of the literature. Inflamm Bowel Dis 2018;24:2339-2347.

58. Jensen MD, Brodersen JB, Kjeldsen J. Capsule endoscopy for the diagnosis and follow up of Crohn's disease: a comprehensive review of current status. Ann Gastroenterol 2017;30:168-178.

59. Lewis BS. Expanding role of capsule endoscopy in inflammatory bowel disease. World J Gastroenterol 2008;14:4137-4141.

60. Yadav A, Heigh RI, Hara AK, et al. Performance of the patency capsule compared with nonenteroclysis radiologic examinations in patients with known or suspected intestinal strictures. Gastrointest Endosc 2011;74:834-839.

61. Rozendorn N, Klang E, Lahat A, et al. Prediction of patency capsule retention in known Crohn's disease patients by using magnetic resonance imaging. Gastrointest Endosc 2016;83:182-187.

62. Rondonotti E. Capsule retention: prevention, diagnosis and management. Ann Transl Med 2017;5:198.

63. Ohtsuka K, Takenaka K, Kitazume Y, et al. Magnetic resonance enterography for the evaluation of the deep small intestine in 
Crohn's disease. Intest Res 2016;14:120-126.

64. Shirasawa T, Hashimoto S, Shimizu K, et al. Effectiveness of using lowdose computed tomography to assess patency in gastrointestinal tracts with a patency capsule. Hepatogastroenterology 2015;62:240-244.

65. Assadsangabi A, Blakeborough A, Drew K, Lobo AJ, Sidhu R, McAlindon ME. Small bowel patency assessment using the patency device and a novel targeted (limited radiation) computed tomographybased protocol. J Gastroenterol Hepatol 2015;30:984-989.

66. Dionisio PM, Gurudu SR, Leighton JA, et al. Capsule endoscopy has a significantly higher diagnostic yield in patients with suspected and established small-bowel Crohn's disease: a meta-analysis. Am J Gastroenterol 2010;105:1240-1248.

67. Yung DE, Har-Noy O, Tham YS, et al. Capsule endoscopy, magnetic resonance enterography, and small bowel ultrasound for evaluation of postoperative recurrence in Crohn's disease: systematic review and meta-analysis. Inflamm Bowel Dis 2017;24:93-100.

68. González-Suárez B, Rodriguez S, Ricart E, et al. Comparison of capsule endoscopy and magnetic resonance enterography for the assessment of small bowel lesions in Crohn's disease. Inflamm Bowel Dis 2018;24:775-780.

69. Triester SL, Leighton JA, Leontiadis GI, et al. A meta-analysis of the yield of capsule endoscopy compared to other diagnostic modalities in patients with non-stricturing small bowel Crohn's disease. Am J Gastroenterol 2006;101:954-964.

70. Voderholzer WA, Beinhoelzl J, Rogalla P, et al. Small bowel involvement in Crohn's disease: a prospective comparison of wireless capsule endoscopy and computed tomography enteroclysis. Gut 2005;54:369-373.

71. Eliakim R, Suissa A, Yassin K, Katz D, Fischer D. Wireless capsule video endoscopy compared to barium follow-through and computerised tomography in patients with suspected Crohn's disease-final report. Dig Liver Dis 2004;36:519-522.

72. Hara AK, Leighton JA, Heigh RI, et al. Crohn disease of the small bowel: preliminary comparison among CT enterography, capsule endoscopy, small-bowel follow-through, and ileoscopy. Radiology 2006;238:128-134.

73. Yablecovitch D, Lahat A, Neuman S, et al. The Lewis score or the capsule endoscopy Crohn's disease activity index: which one is better for the assessment of small bowel inflammation in established Crohn's disease? Therap Adv Gastroenterol 2018;11:1756283X17747780.

74. Ponte A, Pinho R, Rodrigues A, et al. Evaluation and comparison of capsule endoscopy scores for assessment of inflammatory activity of small-bowel in Crohn's disease. Gastroenterol Hepatol 2018;41:245-250.

75. Melmed GY, Dubinsky MC, Rubin DT, et al. Utility of video capsule endoscopy for longitudinal monitoring of Crohn's disease activity in the small bowel: a prospective study. Gastrointest Endosc 2018;88:947-955.

76. Koulaouzidis A, Douglas S, Plevris JN. Lewis score correlates more closely with fecal calprotectin than capsule endoscopy Crohn's disease activity index. Dig Dis Sci 2012;57:987-993.

77. Vernia F, Di Ruscio M, Stefanelli G, Viscido A, Frieri G, Latella G. Is fecal calprotectin an accurate marker in the management of Crohn's disease? J Gastroenterol Hepatol 2020;35:390-400.

78. Kopylov U, Yung DE, Engel T, et al. Fecal calprotectin for the prediction of small-bowel Crohn's disease by capsule endoscopy: a systematic review and meta-analysis. Eur J Gastroenterol Hepatol 2016;28:1137-1144.

79. Egea-Valenzuela J, Alberca-de-Las-Parras F, Carballo-Álvarez F. Fecal calprotectin as a biomarker of inflammatory lesions of the small bowel seen by videocapsule endoscopy. Rev Esp Enferm Dig 2015;107:211-214

80. Bar-Gil Shitrit A, Koslowsky B, Livovsky DM, et al. A prospective study of fecal calprotectin and lactoferrin as predictors of small bowel Crohn's disease in patients undergoing capsule endoscopy. Scand J Gastroenterol 2017;52:328-333.

81. Hale MF, Drew K, McAlindon ME, Sidhu R. The diagnostic accuracy of faecal calprotectin and small bowel capsule endoscopy and their correlation in suspected isolated small bowel Crohn's disease. Eur J Gastroenterol Hepatol 2016;28:1145-1150.

82. Höög CM, Bark L, Broström O, Sjöqvist U. Capsule endoscopic findings correlate with fecal calprotectin and C-reactive protein in patients with suspected small-bowel Crohn's disease. Scand J Gastroenterol 2014;49:1084-1090.

83. Mitselos IV, Katsanos KH, Tatsioni A, et al. Association of clinical and inflammatory markers with small bowel capsule endoscopy findings in Crohn's disease. Eur J Gastroenterol Hepatol 2018;30:861-867.

84. Atreya R, Neurath MF. Current and future targets for mucosal healing in inflammatory bowel disease. Visc Med 2017;33:82-88.

85. Daperno M, Castiglione F, de Ridder L, et al. Results of the $2^{\text {nd }}$ part Scientific Workshop of the ECCO. II: Measures and markers of prediction to achieve, detect, and monitor intestinal healing in inflammatory bowel disease. J Crohns Colitis 2011;5:484-498.

86. Neurath MF, Travis SP. Mucosal healing in inflammatory bowel diseases: a systematic review. Gut 2012;61:1619-1635.

87. Pineton de Chambrun G, Peyrin-Biroulet L, Lémann M, Colombel JF. Clinical implications of mucosal healing for the management of IBD. Nat Rev Gastroenterol Hepatol 2010;7:15-29.

88. Rutgeerts P, Van Assche G, Sandborn WJ, et al; EXTEND Investigators. Adalimumab induces and maintains mucosal healing in patients with Crohn's disease: data from the EXTEND trial. Gastroenterology 2012;142:1102-1111.

89. Cotter J, Dias de Castro F, Magalhães J, Moreira MJ, Rosa B. Validation of the Lewis score for the evaluation of small-bowel Crohn's disease activity. Endoscopy 2015;47:330-335.

90. Niv Y, Ilani S, Levi Z, et al. Validation of the capsule endoscopy Crohn's disease activity index (CECDAI or Niv score): a multicenter prospective study. Endoscopy 2012;44:21-26.

91. Jensen MD, Nathan T, Rafaelsen SR, Kjeldsen J. Diagnostic accuracy of capsule endoscopy for small bowel Crohn's disease is superior to that of MR enterography or CT enterography. Clin Gastroenterol Hepatol 2011;9:124-129.

92. Petruzziello C, Onali S, Calabrese E, et al. Wireless capsule endoscopy and proximal small bowel lesions in Crohn's disease. World J Gastroenterol 2010;16:3299-3304.

93. Flamant M, Trang C, Maillard O, et al. The prevalence and outcome of jejunal lesions visualized by small bowel capsule endoscopy in Crohn's disease. Inflamm Bowel Dis 2013;19:1390-1396.

94. Lazarev M, Huang C, Bitton A, et al. Relationship between proximal Crohn's disease location and disease behavior and surgery: a cross-sectional study of the IBD Genetics Consortium. Am J Gastroenterol 2013;108:106-112.

95. Le Berre C, Trang-Poisson C, Bourreille A. Small bowel capsule endoscopy and treat-to-target in Crohn's disease: a systematic review. World J Gastroenterol 2019;25:4534-4554.

96. Monteiro S, Boal Carvalho P, Dias de Castro F, et al. Capsule endoscopy: diagnostic accuracy of Lewis score in patients with suspected Crohn's disease. Inflamm Bowel Dis 2015;21:2241-2246.

97. Min SB, Le-Carlson M, Singh N, et al. Video capsule endoscopy impacts decision making in pediatric IBD: a single tertiary care center experience. Inflamm Bowel Dis 2013;19:2139-2145.

98. Maunoury V, Savoye G, Bourreille A, et al. Value of wireless capsule endoscopy in patients with indeterminate colitis (inflammatory bowel disease type unclassified). Inflamm Bowel Dis 2007;13:152-155.

99. Lopes S, Figueiredo P, Portela F, et al. Capsule endoscopy in inflammatory bowel disease type unclassified and indeterminate colitis serologically negative. Inflamm Bowel Dis 2010;16:16631668 . 
100. Monteiro S, Dias de Castro F, Boal Carvalho P, et al. Essential role of small bowel capsule endoscopy in reclassification of colonic inflammatory bowel disease type unclassified. World J Gastrointest Endosc 2017;9:34-40.

101. Eliakim R, Yablecovitch D, Lahat A, et al. A novel PillCam Crohn's capsule score (Eliakim score) for quantification of mucosal inflammation in Crohn's disease. United European Gastroenterol J 2020;8:544-551.

102. Tontini GE, Rizzello F, Cavallaro F, et al. Usefulness of panoramic $344^{\circ}$-viewing in Crohn's disease capsule endoscopy: a proof of concept pilot study with the novel PillCam ${ }^{\mathrm{TM}}$ Crohn's system. BMC Gastroenterol 2020;20:97.

103. Tai FWD, Ellul P, Elosua A, et al. Panenteric capsule endoscopy identifies proximal small bowel disease guiding upstaging and treatment intensification in Crohn's disease: A European multicentre observational cohort study. United European Gastroenterol J 2020;9:248-255.

104. Leighton JA, Helper DJ, Gralnek IM, et al. Comparing diagnostic yield of a novel pan-enteric video capsule endoscope with ileocolonoscopy in patients with active Crohn's disease: a feasibility study. Gastrointest Endosc 2017;85:196-205.

105. Voron T, Rahmi G, Bonnet S, et al. Intraoperative enteroscopy: is there still a role? Gastrointest Endosc Clin N Am 2017;27:153-170.

106. Pennazio M, Venezia L, Cortegoso Valdivia P, Rondonotti E. Device-assisted enteroscopy: an update on techniques, clinical indications and safety. Dig Liver Dis 2019;51:934-943.

107. Kawamura T, Yasuda K, Tanaka K, et al. Clinical evaluation of a newly developed single-balloon enteroscope. Gastrointest Endosc 2008;68:1112-1116.

108. Yamamoto H, Ogata H, Matsumoto T, et al. Clinical practice guideline for enteroscopy. Dig Endosc 2017;29:519-546.

109. Despott EJ, Fraser C. Small bowel endoscopy in inflammatory bowel disease. Best Pract Res Clin Gastroenterol 2012;26:279-291.

110. Akerman PA, Agrawal D, Cantero D, Pangtay J. Spiral enteroscopy with the new DSB overtube: a novel technique for deep peroral small-bowel intubation. Endoscopy 2008;40:974-978.

111. Ramchandani M, Reddy DN, Gupta R, et al. Spiral enteroscopy: a preliminary experience in Asian population. J Gastroenterol Hepatol 2010;25:1754-1757.

112. Beyna T, Arvanitakis M, Schneider M, et al. Total motorized spiral enteroscopy: first prospective clinical feasibility trial. Gastrointest Endosc 2021;93:1362-1370.

113. Beyna T, Arvanitakis M, Schneider M, et al. Motorised spiral enteroscopy: first prospective clinical feasibility study. Gut 2021;70:261-267.

114. Yamada A, Watabe H, Oka S, et al. Feasibility of spiral enteroscopy in Japanese patients: study in two tertiary hospitals. Dig Endosc 2013;25:406-411.

115. Wang P, Wang Y, Dong Y, et al. Outcomes and safety of doubleballoon enteroscopy in small bowel diseases: a single-center experience of 1531 procedures. Surg Endosc 2021;35:576-583.

116. Benmassaoud A, Sasson MS, Pamphile JC, et al. The use of balloon-assisted enteroscopy at a large volume centre: a retrospective analysis. J Can Assoc Gastroenterol 2018;1:33-39.

117. Rahman A, Ross A, Leighton JA, et al. Double-balloon enteroscopy in Crohn's disease: findings and impact on management in a multicenter retrospective study. Gastrointest Endosc 2015;82: 102-107.

118. Tun GSZ, Rattehalli D, Sanders DS, McAlindon ME, Drew K, Sidhu R. Clinical utility of double-balloon enteroscopy in suspected Crohn's disease: a single-centre experience. Eur $J$ Gastroenterol Hepatol 2016;28:820-825.

119. Holleran G, Valerii G, Tortora A, et al. The use of single balloon enteroscopy in Crohn's disease and its impact on clinical outcome. Scand J Gastroenterol 2018;53:925-929.
120. Manes G, Imbesi V, Ardizzone S, Cassinotti A, Pallotta S, Porro GB. Use of double-balloon enteroscopy in the management of patients with Crohn's disease: feasibility and diagnostic yield in a high-volume centre for inflammatory bowel disease. Surg Endosc 2009;23:2790-2795.

121. Heine GD, Hadithi M, Groenen MJ, Kuipers EJ, Jacobs MA, Mulder CJ. Double-balloon enteroscopy: indications, diagnostic yield, and complications in a series of 275 patients with suspected small-bowel disease. Endoscopy 2006;38:42-48.

122. Huang Z, Liu X, Yang F, et al. Diagnostic efficacy of doubleballoon enteroscopy in patients with suspected isolated small bowel Crohn's disease. BMC Gastroenterol 2020;20:42.

123. Baniya R, Upadhaya S, Subedi SC, et al. Balloon enteroscopy versus spiral enteroscopy for small-bowel disorders: a systematic review and meta-analysis. Gastrointest Endosc 2017;86:997-1005.

124. Khashab MA, Lennon AM, Dunbar KB, et al. A comparative evaluation of single-balloon enteroscopy and spiral enteroscopy for patients with mid-gut disorders. Gastrointest Endosc 2010;72:766-772.

125. Kim TJ, Kim ER, Chang DK, Kim YH, Hong SN. Comparison of the efficacy and safety of single- versus double-balloon enteroscopy performed by endoscopist experts in single-balloon enteroscopy: a single-center experience and meta-analysis. Gut Liver 2017;11:520-527.

126. Rahmi G, Samaha E, Vahedi K, et al. Multicenter comparison of double-balloon enteroscopy and spiral enteroscopy. J Gastroenterol Hepatol 2013;28:992-998.

127. Gomollon F, Dignass A, Annese V, et al; ECCO. $3^{\text {rd }}$ European Evidence-based Consensus on the Diagnosis and Management of Crohn's Disease 2016: Part 1: Diagnosis and Medical Management. J Crohns Colitis 2017;11:3-25.

128. Chen H, Liu Y, Fu L, Lin X, Fan D, Li C. Clinical utility of doubleballoon enteroscopy in children: A single-centre experience in South China. J Paediatr Child Health 2019;55:188-1893.

129. de Ridder L, Mensink PB, Lequin MH, et al. Single-balloon enteroscopy, magnetic resonance enterography, and abdominal US useful for evaluation of small-bowel disease in children with (suspected) Crohn's disease. Gastrointest Endosc 2012;75:87-94.

130. Di Nardo G, Calabrese C, Conti Nibali R, et al. Enteroscopy in children. United European Gastroenterol J 2018;6:961-969.

131. Di Nardo G, Oliva S, Aloi M, et al. Usefulness of single-balloon enteroscopy in pediatric Crohn's disease. Gastrointest Endosc 2012;75:80-86.

132. Yokoyama K, Yano T, Kumagai H, et al. Double-balloon enteroscopy for pediatric patients: evaluation of safety and efficacy in 257 cases. J Pediatr Gastroenterol Nutr 2016;63:34-40.

133. Broide E, Shalem T, Richter V, Matalon S, Shirin H. The safety and feasibility of a new through-the-scope balloon-assisted enteroscopy in children. J Pediatr Gastroenterol Nutr 2020;71:e6-e11.

134. Ramchandani M, Rughwani H, Inavolu P, et al. Diagnostic yield and therapeutic impact of novel motorized spiral enteroscopy in small-bowel disorders: a single-center real-world experience from a tertiary care hospital (with video). Gastrointest Endosc 2020;93:616-626.

135. Xin L, Liao Z, Jiang YP, Li ZS. Indications, detectability, positive findings, total enteroscopy, and complications of diagnostic double-balloon endoscopy: a systematic review of data over the first decade of use. Gastrointest Endosc 2011;74:563-570.

136. Hirai F, Beppu T, Takatsu N, et al. Long-term outcome of endoscopic balloon dilation for small bowel strictures in patients with Crohn's disease. Dig Endosc 2014;26:545-551.

137. Takenaka K, Ohtsuka K, Kitazume Y, et al. Magnetic resonance evaluation for small bowel strictures in Crohn's disease: comparison with balloon enteroscopy. J Gastroenterol 2017;52:879-888. 
138. Hayashi Y, Yamamoto H, Yano T, et al. A calibrated, smallcaliber tip, transparent hood to aid endoscopic balloon dilation of intestinal strictures in Crohn's disease: successful use of prototype. Endoscopy 2013;45 Suppl 2 UCTN: E373-E374.

139. Hirai F, Andoh A, Ueno F, et al. Efficacy of endoscopic balloon dilation for small bowel strictures in patients with Crohn's disease: a nationwide, multi-centre, open-label, prospective cohort study. J Crohns Colitis 2018;12:394-401.

140. Sunada K, Shinozaki S, Nagayama M, et al. Long-term outcomes in patients with small intestinal strictures secondary to Crohn's disease after double-balloon endoscopy-assisted balloon dilation. Inflamm Bowel Dis 2016;22:380-386.

141. Bamba S, Sakemi R, Fujii T, et al. A nationwide, multi-center, retrospective study of symptomatic small bowel stricture in patients with Crohn's disease. J Gastroenterol 2020;55:615-626.

142. Bettenworth D, Bokemeyer A, Kou L, et al. Systematic review with meta-analysis: efficacy of balloon-assisted enteroscopy for dilation of small bowel Crohn's disease strictures. Aliment Pharmacol Ther 2020;52:1104-1116.

143. El Ouali S, Click B, Holubar SD, Rieder F. Natural history, diagnosis and treatment approach to fibrostenosing Crohn's disease. United European Gastroenterol J 2020;8:263-270.
144. Chang CW, Tu CH, Chou JW, et al. Endoscopic management of strictures in patients with Crohn's disease - A multi-center experience in Taiwan. J Formos Med Assoc 2020;119:1500-1505.

145. Pohl J, May A, Nachbar L, Ell C. Diagnostic and therapeutic yield of push-and-pull enteroscopy for symptomatic small bowel Crohn's disease strictures. Eur J Gastroenterol Hepatol 2007; 19:529-534.

146. Nishida Y, Hosomi S, Yamagami H, et al. Analysis of the risk factors of surgery after endoscopic balloon dilation for small intestinal strictures in Crohn's disease using double-balloon endoscopy. Intern Med 2017;56:2245-2252.

147. Valdés Del Pino Y, Giordano A, Escapa M, et al. Is endoscopic treatment of small bowel strictures effective and safe in patients with Crohn's disease? Rev Esp Enferm Dig 2020;112:284-289.

148. Baars JE, Theyventhiran R, Aepli P, Saxena P, Kaffes AJ. Doubleballoon enteroscopy-assisted dilatation avoids surgery for small bowel strictures: A systematic review. World J Gastroenterol 2017;23:8073-8081.

149. Taida T, Nakagawa T, Ohta Y, et al. Long-term outcome of endoscopic balloon dilatation for strictures in patients with Crohn's disease. Digestion 2018;98:26-32. 